\title{
EL CASAMIENTO DEL PIOJO Y LA PULGA
}

POR

\section{VICENTE T, MENDOZA}

Eso es fácil presumir de dónde, de qué manera o en qué fecha apareció en que el romancillo infantil del Casamiento del Piojo y la Pulga; seguramente que no es tan antiguo que alcance el siglo XVI, puesto que de ser asi lo hubiera citado Rodrigo Caro, en sus famosos diálogos de Los Dias Geniales o Ludricos; no parece ser del XVII, ya que tampoco lo incluye en sus NocheBuenas a lo Divino. Alonso de Ledesma; ni lo consigna ningún romancero. quizá por cớnsiderarlo poco serio y sólo digno de que se ocupen de él los que a la lírica popular infantil se han dedicado.

Es probable que a fines del XVIII si existiera, pero no había alcanzado aún la suficiente difusión por toda España para que los investigadores como don Agustín Durán o Estévanez Calderón le prestaran cuidado consignándolo en sus escritos.

Quizá Fernán Caballero lo tuviera en sus recolecciones y no halló oportunidad de publicarlo en sus obras. Tal vez la popularidad de esta producción solamente alcanzaba a Andalucía y a Extremadura y pertenecia por en tero al mundo de los muchachos. 
La primera publicación aparece en la Enciclopedia (año IV, número 12), presentada por Antonio Machado y Alvarez, bajo sus pseudónimos Muley o Demófilo y más tarde lo reproduce don Francisco Rodriguez Marín en sus "Cantos Populares Españoles, T. I."; mas los citados folkloristas que hacían labor de cultura y de patria hacia el último tercio del siglo XIX, de hecho habian retunido material folklórico de los dos tercios anteriores $y$ aun es presumible que entre su material existieran documentos del siglo XVIII.

Cosa parecida acontecía en México, pues ni en hojas sueltas, ni en libros o revistas había logrado verlo impreso, razón por la cual pensaba que no existía entre nosotros cuando di a la estampa mi artículo "El Apólogo Español en la Producción Folklórica de México", en abril de 1938, en la "Revista Universidad". Bajo esta impresión me di a hurgar y a investigar entre las personas de diversos rumbos del pais, y mediante un corto esfuerzo y en un tiempo verdaderamente reducido, he reunido trece versiones que me permiten deducir algunos puntos acerca de cómo existe en México esta relación en verso, que algunas veces es cantada.

Rodriguez Marin la presenta como coplilla de Nochebuena, procedente de Andalucía, con algunas versiones recogidas en Osuna y Carmona, reproduciéndola con los modismos del lenguaje andaluz, de modo que sirviéndonos de modelo y antecedente, aceptaremos que se trata de un canto tradicional español, propio de muchachos, que ha pasado a América y que existe con vida propia en diversos países en los cuales aún se conservan las manifestaciones populares españolas fuertemente impregnadas.

Casamiento de la Pulga y el Piojo

Cantos Populares Españoles. Francisco Rodriguez Marín. T. I, pág. 74. Ejm. 179. Sevilla, 1882.

La purga y er piojo se quieren casá; por farta de trigo no lo han hecho ya.

Arrun-run, que del arma 'rrun-run.

Salió una jormiga de su jormigá:

-Hágase la boda; yo daré un costá.

-Contentos estamos: ya trigo tenemos. 
Pobres de nosotros, que carne queremos-.

$Y$ respondió un zorro desde lo arto 'un cerro:

-Hágase la boda; yo daré un becerro.

-Contentos estamos: ya carne tenemos.

Pobres de nosotros, que bino queremos-.

Respondió un mosquito desd 'una tinaja:

- Hágase la boda: yo daré una carga.

-Contentos estamos: ya bino tenemos.

Pobres de nosotros, madrina queremos-.

Salió una sigüeña, pescuezo e gayina:

- Hágase la boda; yo soy la madrina.

Contentos estamos; madrina tenemos.

Pobres de nosotros, padrino queremos-.

Responde un ratón, corteza e tocino:

- Hágase la boda; yo seré el padrino.

-Contentos estamos: padrino tenemos.

Pobres de nosotros, que cama queremos.-

Responde ' 1 herizo, tendiendo sus lanas:

-Hágase la boda; yo pongo la cama.

Estando la boda con gran regocijo,

Bino un gato negro, se yebó er padrino.

Biendo la sigüeña 'r pleito inar parao,

pegó un boletio y se fué ar tejao.

Biéndose ' $\mathbf{r}$ piojo en tar soledá.

agarró su purga y se fué accostá.

Perteneťe propiamente al género apológo, pues en su trama intervienen los animalés actuando como personas. Este ejemplo también se agrupa con otros semejantes en los que se relatan bodas fantásticas, tales como las de don Repollo y doña Bersa, descritas por Quevedo en su Parnaso Español (Musa VI, Romance III), al cual alude Rodriguez Marín en sus Notas, y las del Casamiento del Huiltacoche, de fuerte influencia española también, que se acostumbra cantar en la Costa Sur de nuestro país.

También aparece este mismo canto en la ciudad de Badajoz, en Extremadura, sólo que con el carácter de canción de cuna con breve estribillo; don Bonifacio Gil García lo incluye en su Cancionero, aunque no presenta el texto completo. 


\section{Casamiento del Piojo y la Pulga}

Cancionero Popular de Extremadura. Bonifacio Gil García. Badajoz 1931. VII Sección Número 4.

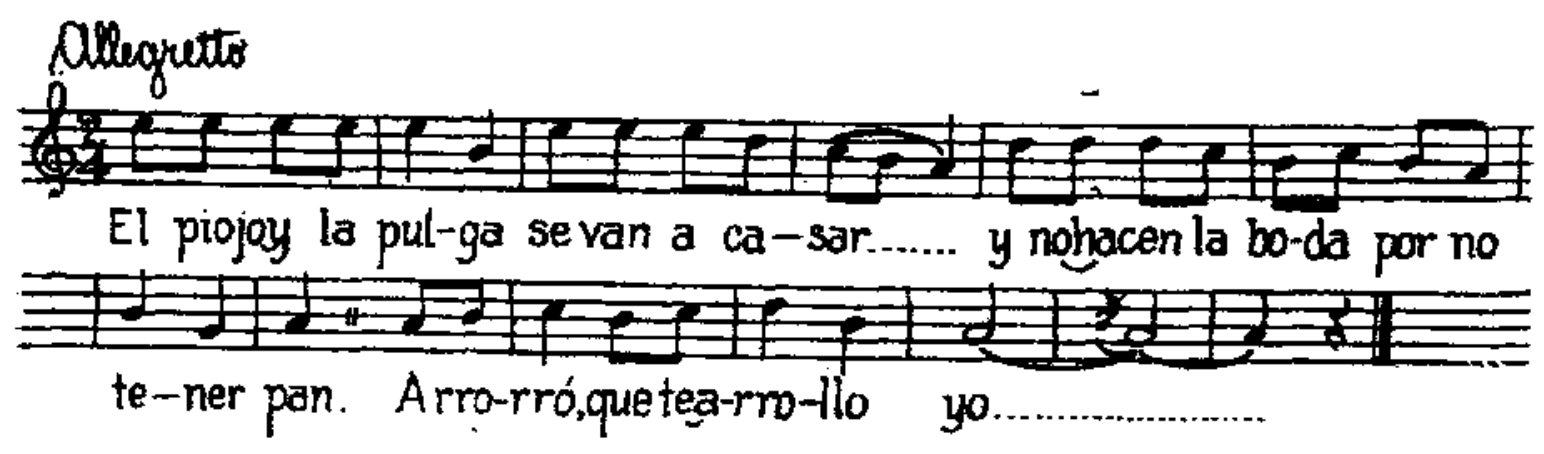

Ell piojo y la pulga se van a casar

y no hacen las bodas por no tener pan.

Arrorró que te arrollo yo...

De los trece ejemplares que tengo a la vista podemos deducir desde luego la difusión que este canto ha logrado en toda la América. Si ordenamos las versiones por su lugar de origen, de Norte a Sur, veremos que van desde Nuevo México hasta Perú y Chile, pudiendo señalar en un plano de la República los lugares en que aparece. Tomaremos el Estado de Nuevo México, de la Unión Americana como el punto más Septentrional y lo marcaremos con el número uno, en seguida el número dos correspondería a la versión procedente de la ciudad de Zacatecas, el tres a la yersión de Tampico, el cuatro a la de Lagos, Jal., el cinco a la de Querétaro, el seis a la de Jalacingo, Ver., el siete a la versión de Toluca, Estado de México, el ocho a la de la Capital de la República y el nueve a la de Coyoacán, D. F., el diez a la versión de Puebla, y dejaremos el número once para la versión de Mérida, Yuc., reservando los números doce y trece para el Perú y Chile, respectivamente.

De aquí deducimos que por el momento y mientras no aparezcan más versiones correspondientes a otros lugares del país, la mayor difusión de este canto la encontramos en los Estados del Centro y hacia el Oriente, teniendo las versiones de Nuevo México y de Yucatán como casos extraordinarics; por lo que respecta a las versiones de Perú y Chile, se explica la presencia de ellas por la emigración de elementos andaluces a dichos países. 
Por lo que respecta a la antigüedad de estas versiones en América se presta a serias conjeturas la presencia de las existentes en los Estados del Centro del pais, las cuales pueden haber sido introducidas en fechas relativamente recientes, dada la afluencia e intercambio de individuos peninsulares en casi toda la República; mas si examinamos los elementos ideológicos y los musicales que las constituyen, entonces se hace preciso ampliar el lapso de existencia en México, así como la fecha de aparición, la cual tendría que remontarse a algo más de un siglo; pues en el mismo caso estarían las versiones de Yucatán, Nuevo México, Perú y Chile. Y si bien es verdad que la afluen-

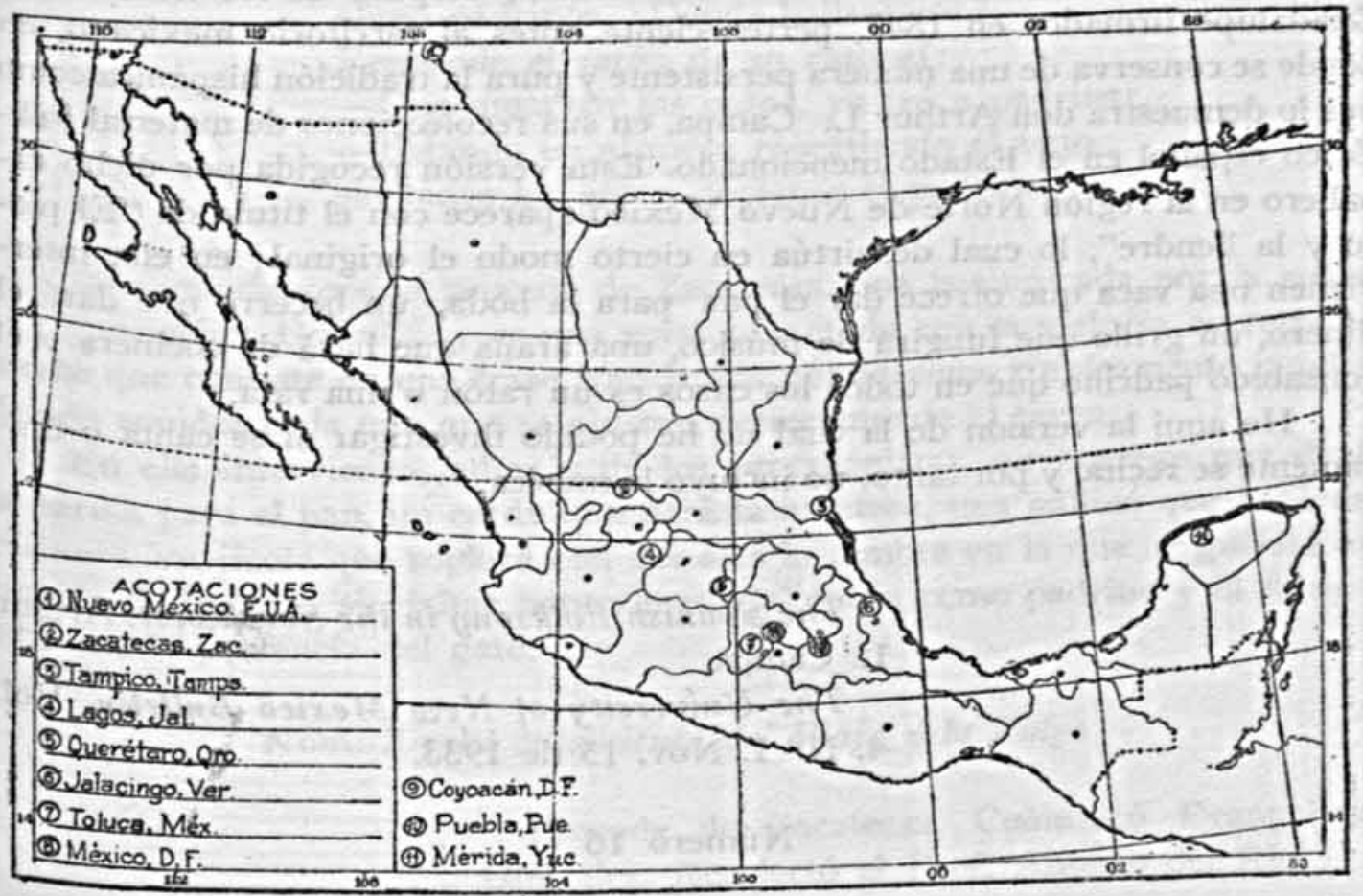

cia de peninsulares en Yucatán ha seguido siendo tan abundante como en el centro del país, en cambio no sucede lo mismo con la versión de Nuevo México, la cual debió haber sido introducida muchos años antes de la anexión del Estado de Nuevo México a la Unión Americana, a mediados del siglo $\mathrm{XIX}$, y en caso análogo estaría la versión peruana que consignara don Ricardo Palma, en sus célebres "Tradiciones", ya que siendo verdadero folklore, debió haberla aprendido en su infancia, poco más o menos también a 
mediados del pasado siglo. Por lo que se refiere a la versión chilena. siendo el dominio del pueblo en la forma en que nos ha sido comunicada, su antigüedad se remontaría a las mismas fechas que las dos anteriores, coincidiendo, más o menos, con la antigüedad que hemos supuesto para las versiones españolas que publicara Rodríguez Marin y Machado Alvarez. Por tanto, no es posible señalar una fecha precisa; pero si aproximada y ésta abarca alrededor de un siglo.

Pasamos ahora a analizar una por una de las versiones $y$ las circunstancias que las caracterizan. La número uno corresponde a Nuevo México, uno de los Estados del Sur de la Unión Americana, después de los tratados de Guadalupe firmados en 1847 , perteneciente antes al territorio mexicano, en donde se conserva de una manera persistente y pura la tradición hispánica como nos lo demuestra don Arthur L. Campa, en sus recolecciones de material folklórico español en el Estado mencionado. Esta versión recogida por dicho caballero en la región Norte de Nuevo México aparece con el título de "El piojo y la liendre", lo cual desvirtúa en cierto modo el original ; en ella intervienen una vaca que ofrece dar el pan para la boda, un becerro que dará el dinero, un grillo que fungirá de músico, una araña que hará de cocinera y el consabido padrino que en todos los casos es un ratón o una rata.

He aquí la versión de la cual no he podido investigar si se canta o únicamente se recita, y por tanto, no incluyo la música.

The Spanish Folksong in the Southzest. Arthur L. Campa.

The University of New Mexico Bulletin. Vol. 4, No 1. Nov. 15 de 1933.

Número 16

Núm. 1.-El Piojo y la Liendre se quieren casar

El piojo y la liendre se quieren casar y no hacen la boda por falta de pan. Responde la vaca desde su corral:

-Que siga la boda que yo daré el pan.

- Que siga la boda, que ya pan tenemos.

Ahora, dinero, ¿dónde lo hallaremos?

Responde el becerro desde su chiquero: 
-Que siga la boda, yo daré dinero.

-Que siga la boda, dinero tenemos.

Ahora quien toque. ¿ Dónde hallaremos?

Responde el grillo desde su grillar:

-Que siga la boda, que yo iré a tocar.

-Que siga la boda, quien toque tenemos.

Ahora quien guise. ¿Dónde hallaremos?

Responde la araña desde su arañal :

-Que siga la boda, que yo iré a guisar.

-Que siga la boda, quien guise tenemos, ahora pađlrinos. ¿Dónde hallaremos?

Responde el ratón de su ratonal:

-Que amarren los gatos, yo iré a padrinar.

-Estando en al mesa repartiendo el vino

suéltanse los gatos, sóplanse el padrino.

La segunda versión procede de Zacatecas; fué comunicada por la señorita Evangelina González y es una versión cantada con la melodia correspondiente que consiste en una frase constituída por motivos rítmicamente iguales de seis sonidos cada uno que se ajustan perfectamente al texto.

En ella intervienen, además de los protagonistas, un borrego que dará la harina para el pan, un cerdo que dará la manteca, una gallina que hará de cocinera,.un jicote que soplará con sus alas la lumbre en la que se guisará la comida de la boda, sin faltar naturalmente el ratón como padrino y el desenlace con la presencia del gato.

S Núm. 2.-El casamiento del Piojo y la Pulga

Procede de Zacatecas. Comunicó Evangelina González. Recolectó el Prof. Alfonso del Río.

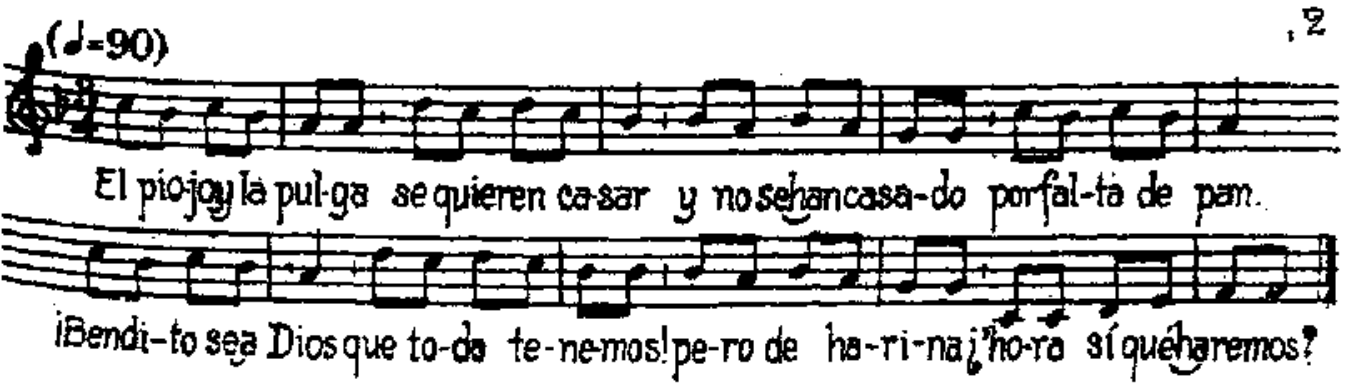


El piojo y la pulga se quieren casar y no se han casado por falta de pan.

:Bendito sea Dios que todo tenemos!

Pero de harina, ¿'ora si que haremos?

Contestó el borrego desde su corral :

- Háganse las bodas, yo doy un costal.

;Bendito sea Dios que todo tenemos!

Pero de manteca i'ora si qué haremos?

Contestó el cochino desde su corral:

-Hágase la boda que manteca aquí hay.

¿Bendito sea Dios que todo tenemos!

Pero de quien guise ¿'ora si qué haremos?

Dijo la gallina desde su corral:

- Háganse las bodas que yo iré a guisar.

¡Bendito sea Dios que todo tenemos!

Pero de quien sople ¿ora si qué harenos?

Contestó el jicote desde su panal:

-Háganse las bodas que yo iré a soplar.

¿ Bendito sea Dios que todo tenemos!

Pero de padrino ¿ ora si qué haremos?

Contestó el ratón en tono ladino:

-Háganse las bodas, yo seré el padrino.

Se hicieron las bodas y hubo mucho vino, soltaron al gato se comió al padrino...

i Ah qué tarugada! lo que sucedió;

Se desató el gato, todo se acabó.

El número tres procede de Tampico, Tamps., y ofrece como dato cronológico seguro el que la señora Concepción Aragón de Toussaint lo sabía hacia el año de 1880. En esta versión intervienen además de los novios un gorgojo que proporcionará el pan para las bodas, un mosquito que cantará en la fiesta, una araña que indudablemente tejerá el velo de la novia, luego aparece como fragmentaria la versión y termina con la elección de padrino y con la muerte del mismo. 
Núm. 3.-El casaniento del Piojo y la Pulga

Procede de 'Tampico 1880. Comunicó la señora Concepción Aragón de Toussaint.

Ed piojo y la pulga se quieren casar, no se hacen tas bodas por falta de pan. Responde el gorgojo desde su trigal :

-Que se hagan las bodas que yo daré el pan. iBendito sea Dios que ya pan tenemos. Sólo de quien cante quién sabe quć haremos! Responde el mosquito desde el mosquital: - Que se haga la boda yo voy a cantar. iBendito sea Dios, quien cante tenemos, sólo de quien hile quién sabe qué haremos!

Responde la araña desde su telar: - Que se haga la boda, que yo voy a hilar. i Bendito sea Dios, quien hile tenemos sólo de quien...

i Bendito sea Dios que todo tenemos, menos quien padrine, quiẻn sabe qué haremos! Responde el ratón desde el ratonal:

- Esscondan al gato yo iré a apadrinar. Y estando en la boda y en gran regocijo

. el malvado gato se comió al padrino.

mente versión número cuatro es procedente del Estado de Jalisco y sumanativa conocida en la población de Lagos de Moreno, lugar de donde es la caraun señora Luz Maria Martín del Campo de $T$. Moreno, que fué quien dé́ camunicó y según su testimonio, la cantaba su madre, hacia los últimos años deĺ siglo pasado.

La importancia que esta versión ofrece es la de ser cantada y la de que cada cuatro hemistiquios de seis sílabas, aparece un estribillo que no tiene el ging de las demás versiones que obran en mi poder. He aqui la melodía y el texto que nos fué proporcionado: 
Núm. 4.-Casamiento del Piojo y la Pulga

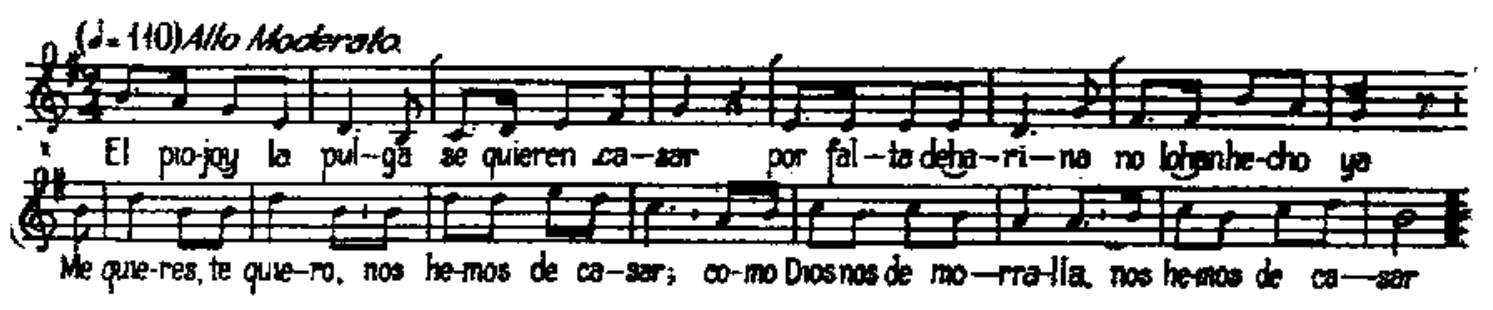

El piojo y la pulga se quieren casar, por falta de harina no lo han hecho ya.

Estribillo:

Me quieres, te quiero,

nos hemos de casar;

como Dios nos dé morralla,

nos hemos de casar.

La quinta versión proporcionada por la señorita Luz Gorráez, procede de Querétaro, Qro., y tiene como circunstancias el ser cantada. En ella intervienen, además de los desposados, el gorgojo que proporcionará el pan, la araña que peinará a la novia y tal vez le teja también el velo; la rana cantará con su entusiasmo envidiable. Luego aparece fragmentario el texto y termina con la elección de padrino que recae en el ratón, y la muerte de éste por la aparición del gato.

He aqui la versión como nos fué comunicada:

Núm. 5.-Casamiento del Piojo y la Pulga

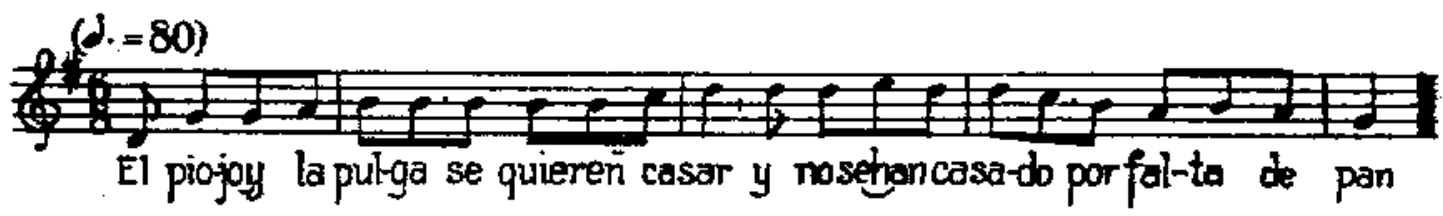

El piojo y la pulga se quieren casar

$y$ no se han casado por falta de pan.

Responde el gorgojo desde el gorgojal :

-Que se haga la boda, que yo daré el pan. 
i Bendito sea Dios que todo tenemos, menos quien nos peine, quién sabe qué haremos! Responde la araña desde el atañal : Que se haga la boda, que yo iré a peinar. i Bendito sea Dios que todo tenemos, menos quien nos cante, quién sabe qué haremos! Responde la rana desde su ranal: Que se haga la boda, que yo iré a cantar.

iBendito sea Dios que todo tenemos, menos de padrino, quién sabe qué haremos! Responde el ratón desde el ratonal: -Escondan al gato, yo iré a apadrinar. $Y$ estando la boda en gran regocijo el malvado gato se comió al padrino.

I a versión número seis nos fué comunicada por una persona de la región de Jalacingo, Esstado de Veracruz, quien además de la versión literaria nos proporcionó la musical que incluimos en su respectivo lugar.

Es ésta, quizá, la más completa de las versiones que poseemos. Ella revela una gran fantasia creadora en los individuos de esta región, ya que el número de animales que participan en las donaciones para que la boda se verifique, se encuentra reforzado por otras que realizan objetos o cosas inanimadas. Revela, además, un sentido de humorismo cuando al solicitar quien vaya a hacer las viandas para la boda se ofrece espontäneamente el zorrillo, que es el animal más fétido que se conoce en México (Mufeta, según Buffon; épatl, nombre que daban a este animal los antiguos aztecas); lo mismo cuando requieren un cura para que los case, se ofrece la lechuza a fungir de sacerdote, quizá por la gravedad y misterio con que se muestra.

He aquí la versión proporcionada por la señora Rosalía Amorós Vda. de Mendoza :

Núm. 6.-Casamiento del Piojo y la Pulga

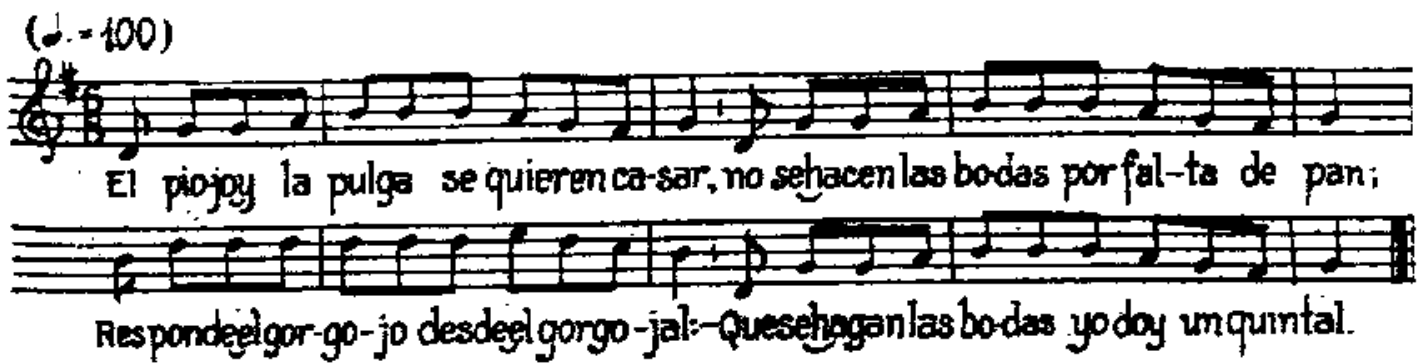


El piojo y la pulga se quieren casar, no se hacen las bodas por falta de pan; responde el gorgojo desde gorgojal:

- Háganse las bodas, yo doy un quintal iBendito sea Dios que todo tenemos! sólo guisanderos, iquién sabe qué haremos! Responde el zorrillo desde el zorrillal:

- Háganse las bodas que yo iré a guisar-. i Bendito sea Dios que todo tenemos, sólo musiquitos, quién sabe qué haremos! Responde el sapito desde su sapal:

-Que se hagan las bodas, que yo iré a tocar. i Bendito sea Dios que todo tenemos! sólo cantadores, quien sabe qué haremos. Responde la rana desde su ranal:

- Que se hagan las bodas, que yo iré a cantar-. ¡Bendito sea Dios que todo tenemos ? sólo bailadores, quién sabe qué hatemos. Responde el grillito desde su grillal :

-Que se hagan las bodas, que yo iré a bailar-. IBendito sea Dios que todo tenemos! sólo del curita, quién sabe qué haremos.

Cantó la lechuza desde el lechuzal:

-Que se hagan las bodas, yo voy a casar-. ¿Bendito sea Dios que todo tenemos! sólo de casita, quién sabe qué haremos. Responde el tarrito desde su tarral:

-Que se hagan las bodas, que yo iré a cercar-. i Bendito sea Dios que todo tenemos! sólo de techito, quién sabe qué haremos. Responde el zacate desde el zacatal.

-Que se hagan las bodas, que yo iré a techar-. i Bendito sea Dios que todo tenemos! $\mathrm{Y}$ todos muy juntos aqui yiviremos.

La séptima versión nos fué proporcionada por la señora Juama Albarrán, de Toluca, Estado de México, y, aunque es muy fragmentaria, tiene como mérito el ser cantada con la melodía que acompañamos; pero ésta es la mis- 
ma con que se canta en todo el pais la cancioncilla intantil muy divulgada con el nombre de la Vindita de Sarta Isabel.

He aqui el fragmento aludido:

Núm. 7.-Casamiento del Piojo y la Pulga

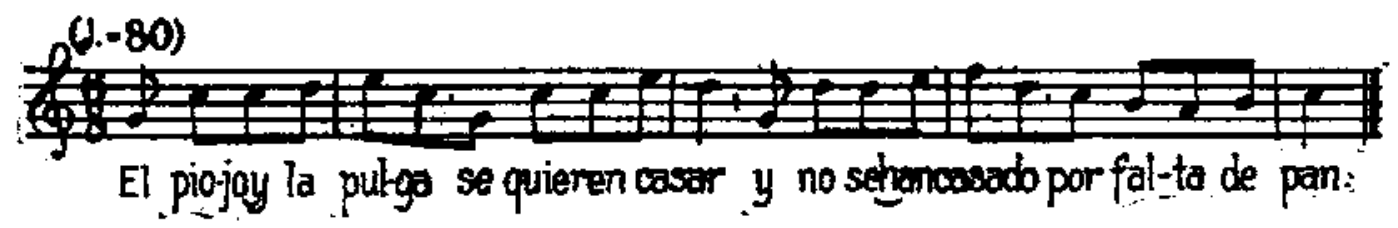

El piojo y la pulga se quieren casar

y no se han casado por falta de pan.

Responde el panadero desde el panadal :

-Que se haga la boda, que yo daré el pan-.

¡Bendito, bendito, bendito sea Dios!

.............. que todo tenemos,

una cosa falta, quién sabe qué haremos.

La octava versión corresponde a la capital de la República y fué proporciomeda por la sefiorita Margarita Prieto. En esta versión, además de los no-vios, intervienen el gorgojo, que da el real que falta para que principie a realizarse in boda, la rana que cantará; el sapo que bailará; el zorrillo que se ofrece a ir a guisar y la rata, que será el padrino de bodas. El texto literario ofrece conto curiosidd el comentario que va haciendo cada uno de los que participan.

He aquí el ejemplo:

Núm. 8.-El Casamiento del Piojo y la Pulga

El piojo y la pulge se ran a casar

y no se han casado por falta de un real.

Responde el gorgojo de su gorgojal :

Que se haga la boda, que yo doy el real

|Bendito sea Dios que todo tenemos!

$Y$ de cantadores, quién sabe qué haremos.

Responde la rana desde sti ranal: 
-Que se haga la boda que yo iré a cantar.

Ay, con mis cantidos, qué bueno va a estar.

I Bendito sea Dios que todo tenemos!

$Y$ de bailarines, quién sabe qué haremos.

Responde el sapito desde su sapal:

-Que se haga la boda, que yo iré a bailar.

Ay, con mis brinquitos, qué bueno va a estar.

i Bendito sea Dios que todo tenemos!

y de guisanderos, quién sabe qué haremos.

Responde el zorrillo de su zorrillal:

-Que se haga la boda que yo iré a guisar.

Ay, con mis olores qué bueno va a estar.

¡Bendito sea Dios que todo tenemos!

$Y$ de padrinito, quién sabe qué haremos.

Responde la rata desde su ratal:

-Amarren al gato, yo iré a apadrinar.

Estaba la boda en gran desatino,

reviéntase el lazo y se come al padrino.

La versión número nueve es procedente de Coyoacán, D. F., y fué proporcionada por María del Refugio Díaz de León. Es bastante cercana a la anterior, pues la boda no se hace por falta de un real; en ella toman participación, además de los novios, la rana, que proporciona el dinero, la araña que bailará, el grillo que cantará, la chinche que irá a fungir de cocinera, la hormiga que desempeñará el papel de músico, la oruga que hará de lavandera y como caso curioso, en esta versión, no aparece la muerte del padrino; quizá sea una versión fragmentaria en la cual se ha olvidado el final: no hemos podido dar con la melodía respectiva con que se canta.

Núrn. 9.-El Casamiento del Piojo y la Pulga

La pulga y el piojo se van a casar

y no hacen la boda por falta de un real.

Responde la rana desde su ranal :

-Que se haga 13 boda, que yo daré un real.

iBendito sea Dios, que (ya) todo tenemos, sólo (de) bailadores, quién sabe qué haremos!

Responde la araña desde su arañal:

-Que se haga la boda, que yo iré a bailar. 
iBendito sea Dios (que) ya todo tenemos, sólo (de) cantadores, quiển sabe qué haremos! Responde un grillo desde su grillal : -Que se haga la boda, que yo iré a cantar. ¿ Bendito sea Dios, que (ya) todo tenemos, sólo (de) guisadera, quién sabe qué haremos! Responde la chinche desde su chinchal: -Que se haga la boda, que yo iré a guisar. ; Bendito sea Dios, que (ya) todo tenemos, sólo (de) musiquita, quien sabe qué haremos! Responde la hormiga desde su hormigal: -Que se haga la boda, que yo iré a tocar. i Bendito sea Dios, que (ya) todo tenemos, sólo (de) lavandera, quién sabe qué haremos! Responde la oruga desde su orugal : -Que se haga la bóda, que yo iré a lavar. i Bendito sea Dios, que (ya) todo tenemos, y por fin la boda la celebraremos.

La versión número diez que es solamente literaria, procede de Puebla y fué comunicada por la señora Maria Cruz Gómez Daza de Quintana. La fecha probable de su existencia en dicha ciudad es de 1890. Ofrece más o menos las circunstancias de otras, sólo variando las funciones de los animales que intervienen, puesto que el mosquito irá a fungir de cantor y la araña de bailador. He aquí el fragmento:

Núm. 10.-El casamiento del Piojo y la Pulga

Procede de Puebla, Pue. 1890. Comunicó la señora María Cruz Gómez Daza de Quintana.

El piojo y la pulga se van a casar, no se hacen las bodas por falta de pan.

Responde una hormiga desde su hormigal:

-Que se hagan las bodas que yo daré el pan.

¡Albricias, albricias!, ya el pan lo tenemos ;

pero ahora la carne ¿de dónde la cogeremos?

Responde el lobo desde aquellos cerros : 
-Que se hagan las bodas, que yo daté becerros.

i Albricias, albricias!, ya carne tenemos;

pero ahora el vino ¿de dónde lo cogeremos?

Responde un mosquito desde su calabacino:

-Que ge hagan las bodas, que yo daté el vino.

i Albricias, albricias!, ya vino tenemos;

pero ahora quien toque ¿de dónde lo cogeremos?

- Responde la araña desde el arañal:

Que se hagan las bodas, que yo iré a töcar.

i Albricias, albricias!, quien toque tenemos;

pèro ahora quien baile ¿ de dónde to cogeremos?

Responde una mona deste su nogal:

Que se hagan las bodas que yo iré a bailar.

i Afbricias, albricias!, quien baile tenemos;

pero ahora quien cante $¿$ de dónde lo cogeremos?

Responde uma rana desde sa ramal :

-Que se hagan las bodas, que yo iré a cantar.

i Albricins, albricias !, quien cante tenemos;

pero ahora madrina ¿de dónde la cogeremos?

Responde una gata desde la cocina:

-Que se hagan las bodas, yo seré madrina.

: Albricias, albricias!, madrina tenemos;

pero ahora padrino t de dónde lo cogeremos?

Responde un ratón de un agujero vecino:

Qute se hagan las bodas, yo será padrino.

$Y$ estando las bodas en todo su tino

saltó la madrina y se comió al padrino.

La versión número once procede de Mérida, Yucatán y es más reciente, puesto que la cattaba hacia 1910 la sefiora Isabel Betancourt. Es probable que no sea propia de la petrínsula, sino más bien tenga influencia cubana, ya que según informes de la misma señora, la aprendió de su padre, quien era nativo de Camagüey, Cuha. Lo importante de esta versión es el ser cantada y aparecer con la melodía respectiva, debiendo notarse, que del mismo modo que la versión precedente de Tóluca se apoya en la frase melódica que acompaña el juego infantil llamado "La viudita de Santa Isabel"; aunque en este caso sufre alguna deformación y cada cuatro hemistiquios de seis silabas van alternados con un interludio melódico equivalente. Otra circunstancia es digna de notarse $y$ es que en esta versión la boda no se realizará entre el piojo y 
la pulga sino entre la chinche y la palga, cosa extrafia; pero si fin y al cabo verdadera dentro del sentimiento infantil que da origen a estas modificaciones:

Núm. 11.-La Chimche y lo Pulga se quieren cosor

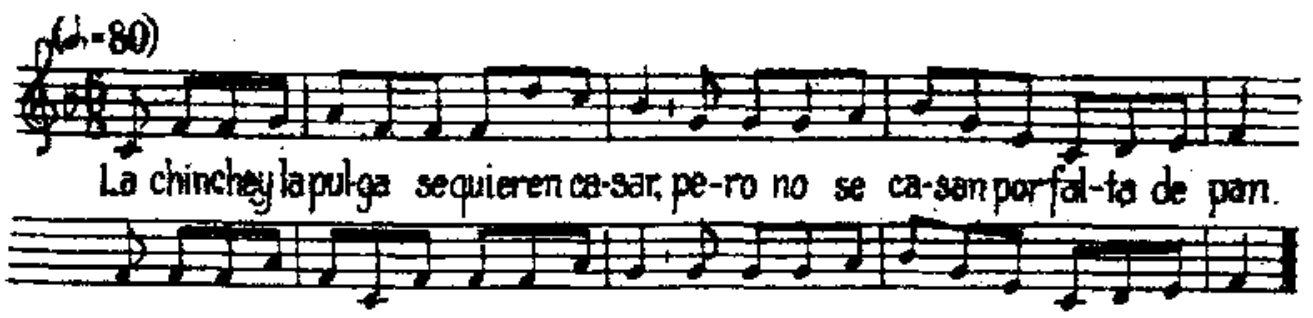

La chinche y al piojo se quieten casar, pero no se casan por falta de pan.

Responde el gorgojo en su gorgojal : que se haga la boda, que yo doy el pan. -Ya no es por el pan, que ya lo tenemos, ahora es por el vino d dónde lo hallaremos? $y$ dice hormiga en la hoja de un pino: -Que siga la boda que yo doy el vino. - Ya no es por vino, que ya to tenemos, ahote es el padrina: ¿dónde lo halbremos? Responde el ratón bajo del molino: -Que amarren al gato, yo soy el padrino. -Ya no es por padrino, que ya lo tenemos, ahora es por madrina ¿dónde la hallaremos? Responde en su nido una golondrina:

- Que siga la boda, yo soy la madrina. -Ya no es por madrina, que ya la tenemos, hoy es por el cura ¿dónde lo hallaremos? Responde el chompipe 1 desde su aposento: -Que sigan las bodas, yo hago el casamiento. - Ya no es por cura, que ya lo tenemos; ahora es por quien baile ¿dónde lo hallaremos? Responde el conejo en su zacatal : -Que sigan las bodas, yo salgo a bailar.

1 Chompip parece derivat de chombito, diminutivos de chombo, que en lenguz maya significa zopilote negro. 
La versión décimasegunda procede del Perú y la incluye don Ricardo Palma en sus Tradiciones Peruanas: "Los escrúpulos de Halicarnaso", T. 3, pág. 435, edición Calpe. Madrid. 1914; mas siendo por naturaleza dicho escritor un archivo folklórico viviente, aunque pone los cuatro versos que a continuación se insertan, en labios de un zapatero del Convictorio de San Carlos, de la ciudad de Lima, es seguro que ellos pertenecían al acervo folklórico del autor, el cual debió haberlos cantado o recitado desde su niñez, hacia 1840. El fragmento que se incluye se acerca, por su aspecto, más que las otras persiones procedentes de México al original andalutz que publicaran Machado Alvarez y Rodriguez Marin; por tanto, todas tres deben tener por lo menos un siglo de antigüedad.

\section{Núm. 12.-Casamiento de la Pulga y el Piojo.}

La pulga y el piojo se quieren casar: por falta de trigo no lo han hecho ya.

La décimatercera versión nos fué comunicada por una persona nativa de Santiago de Chile, la señora Virginia Bravo Letelier, asegurándonos que dicho juego infantil es sumamente popular en su pais. La versión es fragmentaria pero elocuente, y ofrece como circunstancia especial el que cada hemistiquio de seis silabas va seguido en forma alternativa de las palabras "pichingue", "pichinga", que no tienen un significado definido sino más bien pasan por una muletilla infantil.

Núm. 13. Casamiento del Piojo y la Pulga.
E1 piojo y la pulga, pichingue, se quieren casar, pichinga, y no se han casado, pichingue, por falta de pan, pichinga.

Comparados en total los textos ant tiores se pueden deducir dos observaciones:

Primera. E1 texto andaluz pone en primer lugar la pulga y en segundo el piojo, y la razón por la cual no se hace la boda es la falta de trigo.

Segunda. El texto extremeño pone en primer lugar el piojo y la causa de que la boda no se haga la atribuye a falta de pan. 
Comparadas todas las versiones mexicanas, que son once, veremos que nueve de ellas conservan el orden del texto de Extremadura, y sólo dos conservan el orden andaluz, es decir, en estas últimas aparece primero la novia y luego el novio, y de ellas una, substituye la pulga por la chinche. Ocho de las versiones presentan como impedimento de la boda la carencia de pan, una la carencia de harina y dos la falta de un real; de modo que, observado el conjunto, diremos que una gran mayoría parece derivar del texto extremeño y son en cambio muy pocas las que parecen serlo del texto andaluz.

Hay que hacer notar también que la versión peruana resulta ser más fielmente una derivación andaluza, en tanto que la chilena parece serlo de Extremadura.

Como se ve, la suerte que un vástago de la cultura popular española corre al ser trasplantado a territorio americano o a cualquiera otra región de la tierra, en la cual echa raices, es muy varia y sufre modificaciones insospechadas. Es por esto interesante observar cómo esté canto fué sufriendo deformaciones no sólo de un pais a otro en América, sino de una región a otra de nuestra República, $y$ es de ver cómo, ninguna versión de las recogidas por mi, conserva íntegro el desarrollo del modelo y menos aun el final circunstanciado, sino que excita de muy diversas manera la fantasia infantil produciendo numerosos aspectos jdeológicos y aun idiomáticos.

También despierta la curiosidad el ver cómo en la literatura infantil se sistematizan las palabras estableciendo reglas que la Academia de la Lengua no ha sancionado; en este caso se hallan las siguientes, que indican el lugar habitual en que viven los diferentes animales o insectos; primero derivados de un modelo como en el caso de la vaca o el becerro que hablan desde su corral y luego derivados otros de su propio nombre. Así encontramos de grilio, grillal o grillar; de araña, arañal; de ratón, ratonal; de mosquito, mosquital; de gorgojo, gorgojal; de rana, ranal; de zorrillo, zorrillal; de sapo, sapal; de lechuza, lechuzal; de chinche; chinchal; de hormiga, hormigal; o de oruga, orugal. De esta manera, siguiendo este orden hallamos como cosa sumamente curiosa el derivado de tarro, tarral; y el siguiente, que es inconcebible: de panadero, panadal.

He aquí cómo un juego de niños pasa a través del tiempo y del espacio y se esparce como polen en diversos países y en tierras remotas, produciendo siempre frutos frescos y lozanos, conservando, a pesar de todas las vicisitudes, la savia materna que le dió origen.

NorA:

Ya en prensa este artículo, debido a la amabilidad del señor profesor Daniel Ayala, nativo de Mérida, Yucatán, obtuve la versión siguiente que ofrece 
como curiosa circunstancia el estar concebida en idioma maya, lo cual viene a probar que la cancioncilla andaluza que estudiamos fué trasladada a México, a la península yucateca, en una época bastante remota, que permitió, no solamente ser asimilada por el pueblo, sino adaptada al idioma indigena de la región, fenómeno de simbiosis que indudablemente requiere un período más largo de tiempo para su transformación.
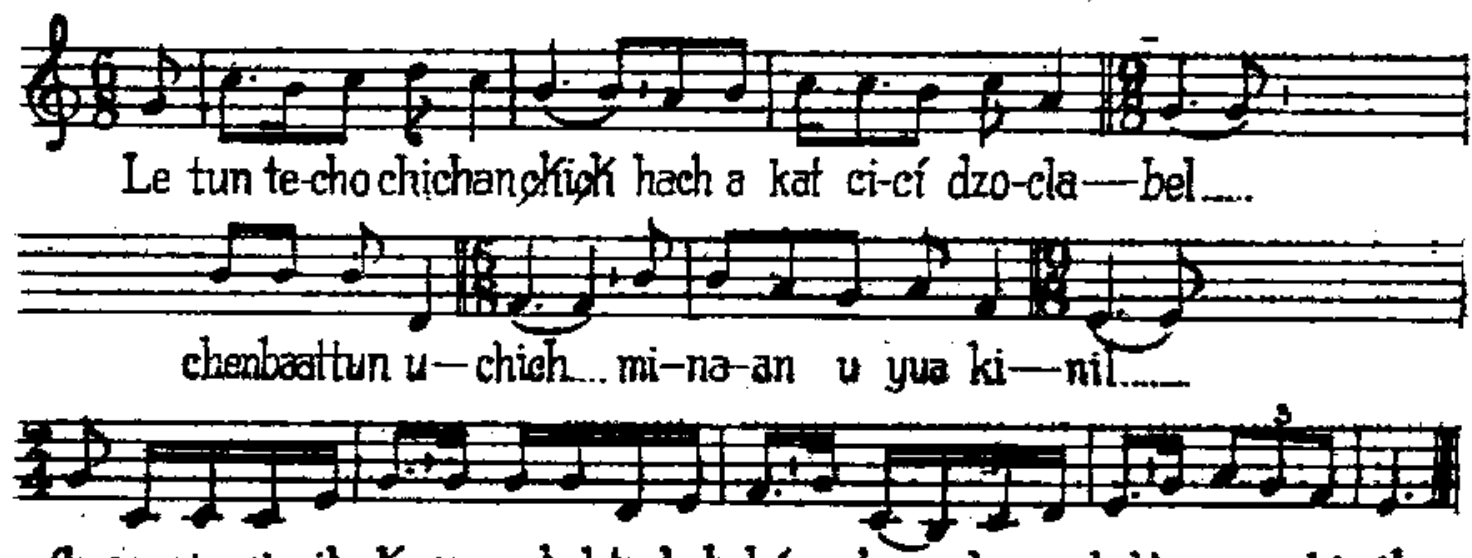

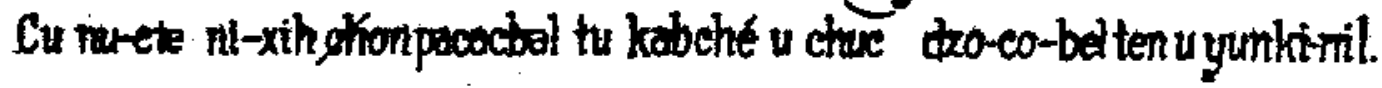

Le tun techo chichan ehich

hach a kat cici dzoclabel

chen baax tun tuttic

mináan a yun kinil.

cu nucic nuxib chom

pacacbal tu kab ché

uchuc dzocabel

ten $u$ yun kinil.

Trachicción proporcionada por el mistno señor Ayala.

Tú que eres pajarito

que te quieres casar,

no podrás hacerlo.

por faltar el sefior cura.

Responde el viejo zopilote, encaramado en una rama:

-Hagase la boda,

que yo seré el cura. 


\section{BIBLIOGR AFIA}

1. Caballero, Fernán.-Obras completas. Miguel Guijarro. Madrid, I880.

2. Campa, Arthur L._-The Spanish Folksong in the Southwest. The University of New Mexico Bulletin. Vol. 4. Núm. 1 .Noviembre 15 de 1933.

3. Caro, Rodrigo.-_Los Dias Geniales o Lúdricos". Cirado pot Rodríguez Marín en "Cantos Populares, Españoles".

4. De Ledesma, Alonso._.."Nochebuenas a lo Divino". Biblioteca de Autores Espanoles. Rivadeneira. Bailli Bailiete. Romancero y Cancionero Religioso. Citada por Rodriguez Marín.

5. Dardn, Aqustin.--"Romancezo General”. Extebanez Calderón. Escenas Andalezas. Novelistas Castellanos. Madrid, 1883.

6. Gill Garcia, Bonifacio.-.."Cancionero Popular de Extremadura". VII. Sección Badajoz, 1931.

7. Machado y Alvarez, Antonio.-En la Enciclopedia. Año IV. Nám. 12.

8. Mendoza, Vicente T.- “Et Apólogo Español en la Producción Folklórica de México". Revista Universidad. Abril de 1938.

9. Palma, Ricardo._-"Tradiciones Peruanas". Los escúpalos de Halicarnaso. T. III. pág. 435. Ed. Calpe. Madrid, 1914.

10. Rodriguez Marin, Francisco._ “Cantos Populares Españoles”. T. I. Sevilla, 1882. 